\title{
Padrões de composição de palavras no Foro Real, de Afonso X
}

\author{
Antonia Vieira dos Santos \\ Universidade Federal da Bahia \\ toniavieira@gmail.com
}

Patterns of Word Composition in Foro Real, by Afonso X

\begin{abstract}
Resumo
No âmbito dos estudos relativos à formaçáo de palavras em perspectiva histórica, a composição tem recebido pouca atenção, comparativamente aos estudos que versam sobre a derivação, em especial os processos sufixativos. Além disso, o estudo linguístico que geralmente acompanha as ediçóes filológicas de textos medievais não contempla, de forma mais aprofundada, a composição de palavras, por vezes reduzida à apresentação de alguns exemplos. Pretende-se com este trabalho, portanto, evidenciar a composiçáo de palavras como um mecanismo presente na sincronia galego-portuguesa, apresentando os principais modelos composicionais disponíveis nesse período da língua e comparando-os com modelos presentes no português e no galego contemporâneos. Os chamados "aglutinados" também são discutidos neste artigo. O corpus utilizado é o Foro Real, de Afonso X (edição de José de Azevedo Ferreira), cuja datação é remetida para a segunda metade do séc. XIII. Na descrição e análise dos compostos, será utilizada a classificação proposta por Rio-Torto e Ribeiro $(2012 ; 2013)$ para as palavras compostas do português contemporâneo. Apresentam-se no corpus, preliminarmente, os seguintes modelos: Nome + Adjetivo $\left([\mathrm{NA}]_{\mathrm{N}}\right)$ como porco montes, Adjetivo + Nome $\left([\mathrm{AN}]_{\mathrm{N}}\right)$, como rico homẽ, e Nome + preposição + Nome $\left([\mathrm{NprepN}]_{\mathrm{N}}\right)$, como molher d'ordin.
\end{abstract}

Palavras-chave

Palavras compostas, aglutinados, Foro Real, galego-português

\section{Sumário}

1. Introdução. 2. Estudos sobre a composição no português contemporâneo e em sincronias pretéritas. 3. Compostos no Foro Real. 3.1. Formas aglutinadas. 4. Discussão dos dados. 5. Conclusôes.
Abstract

Among the studies relating to the formation of words from a historical perspective, composition has received little attention compared to studies that deal with derivation, especially suffixative processes. In addition, linguistic studies that usually accompanies the philological editions of medieval texts does not include, in more depth, the composition of words, which is sometimes reduced to the presentation of a few examples. The aim of this work, therefore, is to show how the composition of words acts as a mechanism present in Galician-Portuguese synchrony by presenting the main compositional models available in that period of the language and comparing these with models present in contemporary Portuguese and Galician. The socalled "agglutinated" forms are also discussed in this article. The corpus utilized is Foro Real, by Afonso X (edited by José de Azevedo Ferreira), which is dated from the second half of the thirteenth century. The classification proposed by Rio-Torto and Ribeiro (2012; 2013) for compound words from contemporary Portuguese will be employed in the description and analysis of compounds. The following models are presented preliminarily in the corpus: Name + Adjective $\left([\mathrm{NA}]_{\mathrm{N}}\right)$ as porco montes, Adjective $+\mathrm{Name}\left([\mathrm{AN}]_{\mathrm{N}}\right)$, as rico homẽ, and Name + preposition + Name $\left([\mathrm{NprepN}]_{\mathrm{N}}\right)$, as molher d'ordin.

Keywords

Compounds, agglutinated forms, Foro Real, Galician-Portuguese language

\section{Contents}

1. Introduction. 2. Studies on the composition in the contemporary Portuguese and past synchronies. 3. Compounds in Foro Real. 3.1. Agglutinated forms. 4. Discussion of data. 5. Conclusions.

Este trabalho, que se insere em um projeto mais amplo que consiste no estudo dos compostos e dos mecanismos de composição de palavras na sincronia galego-portuguesa (séc. XII ao XIV), foi desenvolvido com o apoio do PRODOC/UFBA. 


\section{Introdução}

No âmbito dos estudos relativos à formação de palavras em perspectiva histórica, a composição tem recebido pouca atenção, comparativamente aos estudos que versam sobre a derivação, em especial sobre os processos sufixativos. Além disso, o estudo linguístico que geralmente acompanha as edições filológicas de textos medievais não contempla, de forma aprofundada, os mecanismos de formação de palavras, incluindo a composição de palavras, por vezes reduzida à apresentação de alguns exemplos. No caso específico do Foro Real, o seu editor nos diz: "No que diz respeito à formação das palavras, limitar-nos-emos a apresentar a lista dos sufixos e dos prefixos empregados no texto" (Ferreira 1987: 374).

Pretende-se com este trabalho, portanto, evidenciar a composição de palavras como um mecanismo presente no galego-português, apresentando os principais modelos composicionais disponíveis nesse período da língua e comparando-os com modelos presentes no português e no galego contemporâneos. Também serão analisadas algumas formas aglutinadas, cujo antecedente histórico imediato é um composto sintagmático. O corpus utilizado é a versão portuguesa (ou galego-portuguesa) do Foro Real, de Afonso X (edição preparada por José de Azevedo Ferreira), cuja datação é remetida para a segunda metade do séc. XIII. Na descrição e análise das palavras compostas, será utilizada a classificação proposta por Rio-Torto e Ribeiro (2012; 2013) para os compostos do português contemporâneo.

\section{Estudos sobre a composição no português contemporâneo e em sincronias pretéritas}

Os estudos abordando a formação de palavras em fases pretéritas da língua portuguesa têm recebido bastante atenção, ao longo dos últimos anos, principalmente no que diz respeito a aspectos derivacionais, como a prefixação e a sufixação. A composição, por sua vez, tem gerado poucos estudos na perspectiva histórica, diferentemente dos estudos que têm como foco a sincronia atual ${ }^{1}$. Muitas dissertações e teses têm sido desenvolvidas sobre a composição em português, à luz de variadas perspectivas teóricas. Certamente que no âmbito teórico a composição produz inúmeras discussões no que diz respeito a sua própria definição, ao seu lugar na arquitetura da gramática, a fronteiras entre os domínios da morfologia e da sintaxe, ao seu papel na classificação tipológica das línguas (ponto de vista tipológico/universal), ao seu papel como mecanismo de ampliação do léxico das línguas naturais, aos processos cognitivos ativados

1 Nesse sentido, é pioneiro o trabalho de Xoán L. Blanco Valdés sobre as palavras compostas em galego-português, publicado na revista Verba (1985). 
na sua formação, entre outros aspectos. Portanto, a composição de palavras suscita questões de natureza variada, pertinentes ao campo de estudo da língua e da linguagem. Especificamente sobre a composição no português contemporâneo, destacamse os trabalhos desenvolvidos por Graça Rio-Torto e Sílvia Ribeiro, da Universidade de Coimbra - Portugal, que, com base em uma metodologia que leva em conta, na análise dos compostos, a natureza categorial, morfológica e semântica das bases e as relações morfossemânticas e morfossintáticas estabelecidas entre os constituintes do composto, além dos padrões flexionais, refinam a classificação dos tipos disponíveis em português.

Nesse sentido, a investigação sobre a composição em textos pertencentes a estados pretéritos da língua se apresenta como complementar, pois os dados registrados podem evidenciar determinados comportamentos relacionados à formação e ao emprego dos compostos. Parte-se, primeiramente, da informação presente em obras que abordam a composição na língua latina. A concepção de composição que se apresenta em obras como a de Meillet e Vendryès (1953), por exemplo, é distinta da concepção depreendida em gramáticas do português moderno. Os referidos autores distinguem compostos de justapostos, levando em consideração a acentuação e o comportamento flexional, o que justifica as denominações "compostos perfeitos" e "compostos imperfeitos", utilizadas por alguns autores de gramática histórica do português, como Nunes (1956) e Coutinho (1958).

O aspecto gráfico (ou a “ilusão da escrita”), aliado ao comportamento morfossintático, parece exercer influência na percepção de formas compostas. Assim, tanto a flexão à direita, não interna, como o uso do hífen, parecem consolidar a natureza compositiva de certas combinações de palavras. No caso do português, o critério da flexão externa aplica-se apenas aos compostos morfológicos e às estruturas $[\mathrm{VN}]_{\mathrm{N}}$, $[\text { PrepN }]_{N},[\mathrm{AdvN}]_{\mathrm{N}}$. Em referência ao hífen, o acordo ortográfico assinado pelos países lusófonos em 1990 ajudou a minimizar a importância do critério de identificação de compostos através desse sinal gráfico, bastante inconsistente, tendo em vista que muitas palavras compostas que apresentam elemento de ligação perderam o hífen, a exemplo de pé de moleque e ponto e vírgula (Houaiss e Villar 2009, s.u. pé e ponto, respectivamente).

Em referência aos textos pertencentes a sincronias pretéritas, não se pode contar apenas com o aspecto gráfico e com o comportamento morfossintático das unidades polilexicais. Por inexistir o hífen nos textos pertencentes à época medieval e pelo fato de os compostos portugueses não se reduzirem aos compostos morfológicos, torna-se necessário analisar as combinações de palavras com base no seu valor referencial, isto é, observar se apresentam unidade semântica, e na sua recorrência em um mesmo texto ou em diferentes textos, preferencialmente do mesmo período. Nesse trabalho de reconhecimento de formas compostas, os glossários elaborados pelos editores de textos e os corpora disponíveis na internet são de inestimável relevância para 
o pesquisador. Esses materiais são fundamentais para a verificação de ocorrência de unidades lexicais e de sua unidade semântica.

Tendo em vista que o caráter analítico predomina no âmbito dos compostos portugueses, fato que leva esses compostos a apresentarem uma estrutura análoga à da sintaxe livre, postula-se, para identificação de um verdadeiro composto, a aplicação de alguns testes, entre os quais destacam-se: (i) a impossibilidade de inserção de materiais linguísticos no interior do composto; (ii) a impossibilidade de adjetivação parcial; e (iii) a impossibilidade de operações de determinação no interior do composto (cf. Ribeiro e Rio-Torto 2013: 387-390).

- [livro de cozinha] fascinante/*livro fascinante de cozinha

- [livro de cozinha] novo/*livro de [cozinha nova]

- fim de semanalfim da semana

Buscou-se aplicar esses testes a dados recolhidos do texto do Foro Real, mas a própria especificidade da língua desse período indicia que o impacto desses testes talvez tenha de ser minimizado. As combinações cuja estrutura não se distingue da estrutura de frases sintáticas construídas regularmente - [NA] Nome + Adjetivo, [AN] Adjetivo + Nome, [NprepN] Nome + preposição + Nome, [NprepDN] Nome + preposição + determinante + Nome - tornam mais difícil a tarefa de quem se propõe a estudar as palavras compostas em português. Contudo, nesse grupo, as construções em que estão envolvidos também elementos gramaticais, como o padrão [NprepN], são as que impõem maior dificuldade na sua delimitação, não sendo consensual a sua inclusão no âmbito dos compostos ${ }^{2}$.

\section{Compostos no Foro Real}

O Foro Real caracteriza-se por ser uma obra legislativa, de autoria de Afonso X, redigida entre 1252 e 1255, cuja tradução para o português (ou galego-protuguês) se deu na segunda metade do séc. XIII, e da qual se conhece um único manuscrito (Maço $6^{\circ}$ de Forais Antigos, no 4 do ANTT). A edição utilizada, como já foi referido, é a de José de Azevedo Ferreira (1987), publicada em dois volumes, um correspondente à edição e ao estudo linguístico do texto e outro correspondente ao glossário. Segundo Ferreira (1987: 488):

2 Moyna (2011), por exemplo, considera que os compostos são criados exclusivamente pela combinação de constituintes possuidores do traço [+Lexical]. Dessa forma, no seu estudo sobre as palavras compostas em espanhol, não trata das construções [Nome + preposição + Nome] e [Nome + preposição + determinante + Nome], exemplificadas por dulce de leche e cuerno de la abundancia, respectivamente, pois estas incluem categorias funcionais em sua estrutura interna. 
A análise estatística permitiu-nos verificar uma certa pobreza do vocabulário, pois há um predomínio das palavras gramaticais (58\%) sobre as palavras plenas, uma quase ausência de adjectivos qualificativos, uma percentagem de verbos superior à dos substantivos, o predomínio do futuro do conjuntivo e uma ausência quase total da $1^{\mathrm{a}}$ e $2^{\mathrm{a}}$ pessoas gramaticais. Estas características que os dados estatísticos nos revelaram parecem estar de acordo com a própria natureza do texto foral, pois põem em destaque o grande valor atribuído ao verbo e, através dele, a acção do legislador e a sua intervenção.

A expectativa em relação ao texto do Foro Real (e ainda outros de natureza jurídica) é, portanto, deparar-se com escassos exemplos de compostos ${ }^{3}$. Nesse sentido, Ferreira (1987: 374) aponta que "[e]ncontramos palavras compostas que já caíram em desuso (exemplos: fudodinculi, mayordomo) e outras que ainda hoje são utilizadas". No entanto, nas páginas que se seguem à citação são abordados apenas os sufixos e os prefixos, nessa ordem. Ressalte-se, ainda, que os exemplos de compostos arrolados por Ferreira correspondem a formas aglutinadas, que têm como antecedentes históricos sintagmas latinos.

Partimos, portanto, da observação de compostos com estrutura sintagmática, revestidos dos padrões $[\mathrm{NN}]_{\mathrm{N}},[\mathrm{VN}]_{\mathrm{N}},[\mathrm{NA}]_{\mathrm{N}},[\mathrm{AN}]_{\mathrm{N}}$ e $[\mathrm{NprepN}]_{\mathrm{N}}$. Os chamados "compostos aglutinados" também foram registrados, embora, como Mattoso Câmara Jr. (1998: 38), defendamos que se trata de palavras simples, ou, nas palavras do autor, "a perda de uma justaposição na língua”, cuja estrutura não permite, em muitos casos, o estabelecimento de fronteiras morfológicas que possibilitam identificar o seu antecedente sintagmático. Os compostos morfológicos, caracterizados pelos radicais de natureza erudita - latina ou grega - não são esperados nesse momento da língua.

A concepção de composto adotada nesse estudo busca ser abrangente, como a que se depreende em Ribeiro (2006, 2010), Rio-Torto e Ribeiro (2009; 2012), Ribeiro e Rio-Torto (2013), Bustos Gisbert (1986), Val Álvaro (1999), entre outros, contemplando combinações de palavras que, embora coincidindo com sintagmas livres da língua, correspondam a uma unidade semântica. Nesse sentido, foram registrados 06 compostos $[\mathrm{NA}]_{\mathrm{N}}, 07[\mathrm{AN}]_{\mathrm{N}}, 11[\mathrm{NprepN}]_{\mathrm{N}}, 03[\mathrm{AdvN}]_{\mathrm{N}}^{4}, 01[\mathrm{NumN}]_{\mathrm{N}}$ e 01 $[\text { PronN }]_{\mathrm{N}}$. Não foram registrados os padrões $[\mathrm{VN}]_{\mathrm{N}}$ e $[\mathrm{NN}]_{\mathrm{N}}$, bastante comuns na

3 Maia (1986: 950-951), em relação aos documentos notariais de caráter privado que analisou, também chama a atenção para a "pobreza lexical" desse tipo de documentação, mas ressalta a sua importância para estudos de caráter lexical: "É certo que os documentos notariais manejam um vocabulário relativamente reduzido. No entanto, se se eliminarem as fórmulas jurídicas constantemente repetidas, o vocabulário, ainda que relativamente escasso, pertence a uma terminologia viva, associada à vida quotidiana [...]".

4 Embora as formas maldizentes e malfeytor possam também corresponder à estrutura $[\mathrm{AdvA}]_{\mathrm{A}}$, decidimos classificá-las inicialmente como $[\mathrm{AdvN}]_{\mathrm{N}}$, juntamente com malqueréça, tendo em vista que funcionam no texto como substantivos: "[...] e por amor que tollamos razon dos maldizentes do mal" (FR I.140); “[...] seya ben aguardada dos ladroes e malfeytores" (FR II.390). 
língua moderna. Compostos com essas estruturas (com exceção de [AdvN]) correspondem, de acordo com a perspectiva de Ribeiro e Rio-Torto (2013: 400), a compostos sintagmáticos, definidos como "aqueles cuja estrutura segue os padrões próprios das estruturas sintáticas do português". O Quadro 1 resume os resultados da recolha realizada no Foro Real.

\begin{tabular}{|c|c|}
\hline Padrões composicionais & Exemplos \\
\hline$[\mathrm{NA}]_{\mathrm{N}}$ & porco montes, escriuã publico, ome boo, Spiritu Sancto, tabalió publico, taballioes iurados \\
\hline$[\mathrm{AN}]_{\mathrm{N}}$ & $\begin{array}{c}\text { nova ley, rico homẽ ricoome, Sancta Eygreya, Sancta Maria, Santa Scriptura, Sancta } \\
\text { Trijdade, publicos tabelliones }\end{array}$ \\
\hline$[\mathrm{NprepN}]_{\mathrm{N}}$ & $\begin{array}{l}\text { carta de pessoaria, homẽ d'ordẽ omẽ d'ordin } \sim \text { omẽ d'ordĩe ome d'ordẽ, maestre de } \\
\text { chagas, molher d'ordin, filho de beençon, molher de beençon, filho dalgo, manceba em } \\
\text { cabellos, ordinado de pistola, [ordinado] d'auangello, [ordinado] de missa }\end{array}$ \\
\hline$[\mathrm{AdvN}]_{\mathrm{N}}$ & maldizentes, malfeytor, malquerẽça mal querença \\
\hline$[\mathrm{NumN}]_{\mathrm{N}}$ & meio dia \\
\hline$[\text { PronN }]_{N}$ & Nostro Senhur \\
\hline
\end{tabular}

\section{QUADRO 1. PADRÕES COMPOSICIONAIS NO FORO REAL}

No que diz respeito às construções com o padrão $[\mathrm{NA}]_{\mathrm{N}}$, registraram-se porco montes, escriuã publico, ome boo, Spiritu Sancto, tabaliõ publico e taballioes iurados, este último apenas na forma pluralizada. Destaca-se, dessa relação, a forma tabaliõ publico, a qual apresenta uma forma alternante com a ordem determinante-determinado, registrada apenas na sua forma plural, publicos tabelliones:

- E se nõ forẽ feytas per mao do tabaliõ publico, chame o alcayde aquel contra quẽ estas cartas sõ feytas. (FR II.594) $)^{5}$

- Outauo titulo dos escriuaos que son publicos tabelliones. (FR I.13)

O lexema tabelião também surge com o modificador iurado, equivalendo, nesse caso, a escrivão público, conforme se observa no trecho a seguir:

- enas uillas todas seyan postos escriuaos poblicos a que chamen taballioes iurados (FR I.497)

5 Citam-se, nas transcrições dos exemplos, a etiqueta $F R$ (= Foro Real), seguida do número do capítulo, em algarismos romanos, e da linha, de acordo com a edição de José de Azevedo Ferreira. 
É preciso ressaltar que, apesar de estas formas terem sido registradas como potenciais compostos, a forma tabelião também aparece sem qualquer modificador:

- Os escriuaes publicos e taballioes ponhã enas cartas que fezerẽ o ano e o mes e o dia (FR II.575)

Os compostos com a estrutura $[\mathrm{AN}]_{\mathrm{N}}$ foram: nova ley, rico homẽ, Sancta Eygreya, Sancta Maria, Santa Scritura, Sancta Trijdade e o já comentado publicos tabelliones. No caso de nova ley, Sancta Eygreya e Santa Scritura, considerou-se tratar-se de um caso especial de metonímia, denominado de antonomásia, em que o nome da entidade é substituído por uma expressão linguística composta que, além de invocar qualidade, invoca características ou traços que permitem identificar o nome substituído, e, consequentemente, a entidade denotada: o Novo Testamento, a igreja católica e a bíblia, respectivamente. O composto rico homẽ será abordado no âmbito dos aglutinados.

Em relação às estruturas $[\mathrm{NprepN}]_{\mathrm{N}}$, observem-se, no Quadro 1, aquelas cujo complemento é de beençon: filho de beençon e molher de beençon, significando respectivamente 'filho legítimo' e 'mulher casada, com matrimônio abençoado pela igreja', de acordo com Ferreira (1987, vol. II). Similar estrutura, em que o mesmo complemento modifica nomes distintos, é manceba en cabellos, e a forma alternante menia en cabelos,

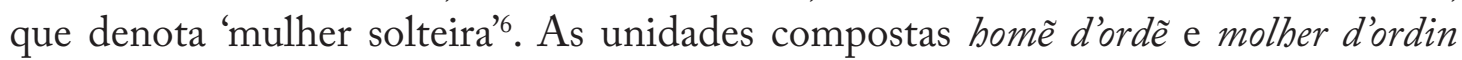
também se caracterizam pelo sintagma preposicionado em comum; no entanto, os núcleos nominais correspondentes vão marcar a oposição de natureza heteronímica entre masculino e feminino: 'religioso' x 'religiosa'. No caso das construções ordinado de pistola, [ordinado] d'auangello e [ordinado] de missa, o núcleo nominal, presente apenas na primeira sequência da série, constitui uma série classificatória, cabendo, ao complemento, a formação de hipônimos, significando, respectivamente: 'subdiácono', 'diácono' e 'presbítero' (Ferreira 1987, s. v. ordẽar). Essa tendência de fazer figurar, na função de núcleo, um constituinte nominal semanticamente "aberto" à formação de séries léxicas mais ou menos alargadas é uma característica marcante da estrutura $[\mathrm{NprepN}]_{\mathrm{N}}$. E o fato de serem, em regra, semanticamente composicionais torna, sem dúvida, essa estrutura produtiva.

Além dessas formas, foram registrados carta de pessoaria e maestre de chagas, este último apresentando a variante maestres das chagas, cuja estrutura apresenta um elemento determinante do nome. Destaque-se a primeira dessas construções, em que o sentido de 'procuração' manifesta-se também apenas sob a forma pessoaria:

6 As mulheres eram assim denominadas porque podiam trazer o cabelo solto, diferentemente das mulheres casadas, que traziam o cabelo sob uma espécie de touca. 
- e u que diser que é alleo mostre pessoarya per que possa demandar ou deffender (FR I.425)

Observa-se, nesse caso, que pode ter ocorrido a redução ao modificador (com abundantes registros nos textos arcaicos e nos modernos), aparentemente sem prejuízo para a interpretação do composto: carta de pessoaria > pessoaria. A redução ao determinante se justifica, pois é o modificador que representa o específico no conteúdo semântico do composto (Bustos Gisbert 1986: 85). No caso de maestre de chagas/maestres das chagas 'médico com especialidade no tratamento de feridas', trata-se de um composto em que a preposição de vem ora sozinha, ora contraída com o artigo definido, fato que, no entanto, não desconstroi a unidade semântica da estrutura. Quanto ao composto fllho dalgo, ele será abordado no âmbito dos aglutinados.

Os itens lexicais registrados como exemplos do padrão $[\mathrm{AdvN}]_{\mathrm{N}}$ constituem, na realidade, formas compostas já em latim: maldizente < lat. MALEDĪCENS, NTIS 'que diz mal de, que injuria e ofende com palavras'; malfeytor < lat. MALEFĀCTOR, ŌRIs 'que causa mal, criminoso'7. A forma malquerẽça é apontada, no dicionário Houaiss e Villar (2009), como uma forma derivada de malquerer, e esta, de mal + querer, uma construção vernácula, portanto, evidenciando que mal- se liga a verbos. A grande questão que rodeia este tipo de estrutura é a dificuldade de se definir se as estruturas em que mal- (e bem-) figura como primeiro elemento possuem caráter prefixal ou composicional. Essa questão não será aprofundada neste trabalho, mas se adianta a tendência, nos estudos morfológicos atuais (consultar, por exemplo, Gonçalves 2011), de considerar a prefixação e a composição como processos integrantes de um continuum.

Para finalizar, os padrões $[\mathrm{NumN}]_{\mathrm{N}}$ e $[\text { PronN }]_{\mathrm{N}}$, exemplificados, no corpus, por meio dia e Nostro Senhur, este último registrado por Cunha e Lindley Cintra (1985) (Nosso Senhor).

Em relação ao comportamento flexional, registraram-se exemplos dos seguintes padrões:

Said Ali (1964: 260) aponta que "[q]uando se estuda o fenômeno da composição dentro do domínio de certo idioma, deve-se atender principalmente ao que esse idioma tem produzido com seus próprios recursos", acrescentando que "[n]ão servem de prova para os fatos palavras compostas pré-existentes à formação do dito idioma, ou importadas de outras línguas, dando a impressão de palavras simples". Assim, para o padrão $[\mathrm{NN}]_{\mathrm{N}}$, o autor ressalta que "[v]ários dos termos assim constituídos que andam disseminados pelo nosso léxico, não têm valor para a análise, por serem traduções ou aportuguesamentos de expressões que tiveram seu berço fora de Portugal". Seria o caso de couve-flor, beterraba, café-concerto, papel-moeda, astro-rei, entre outros. Apesar de pertinente, a observação de Said Ali deve ser relativizada, pois essas palavras podem servir como modelo para a formação de novos compostos em português com a estrutura $[\mathrm{NN}]_{\mathrm{N}}$. 


\begin{tabular}{|c|c|c|}
\hline$[\mathrm{NA}]_{\mathrm{N}}$ & {$[\mathrm{AN}]_{\mathrm{N}}$} & {$[\mathrm{NprepN}]_{\mathrm{N}}$} \\
\hline porcos montes $\underline{e s}$ & ricos omees $\sim$ rycos hoomes & omees d'ordĩ \\
\hline escriuaos poblicos & \multirow{2}{*}{ publicos tabelliones } & maestres das chagas \\
\hline $\begin{array}{c}\text { omees boos } \sim \text { omes boos } \sim \\
\text { homees boos }\end{array}$ & & molheres d'ordĩ \\
\hline
\end{tabular}

\section{QUADRO 2. PADRÕES FLEXIONAIS DOS COMPOSTOS DO FORO REAL}

Como se pode observar no Quadro 2, a flexão de número incide sobre os dois constituintes, no caso de compostos $[\mathrm{NA}]_{\mathrm{N}}$ e $[\mathrm{AN}]_{\mathrm{N}}$, sobre o elemento da esquerda, correspondente ao núcleo, quando se trata de compostos $[\mathrm{NprepN}]_{\mathrm{N}}$. As construções com o advérbio mal-, não explicitadas no Quadro 2, fazem o plural na fronteira direita: maldizentes e malfeytores.

\subsection{Formas aglutinadas}

Partindo-se da idéia de Mattoso Câmara Jr. (1998: 38) de que a aglutinação é "um conceito meramente fonológico e diacrônico", serão considerados como aglutinados, neste estudo, aquelas formas oriundas de sintagmas portugueses, cuja perda de substância fônica seja observável por meio do registro gráfico (dificultando, por vezes, a identificação de fronteiras entre os constituintes), e aquelas formas derivadas de sintagmas latinos, cujo processo de aglutinação nem sempre se evidencia ter se iniciado já em latim ou em vernáculo. É óbvio que algumas formas aglutinadas, representantes históricas de primitivos sintagmas, não evocam o estado anterior de duas palavras justapostas, principalmente quando se trata de lexemas derivados de justaposições latinas. Nessa situação, os elementos que entraram na formação de determinada palavra não são mais facilmente reconhecidos. Os exemplos do Foro Real são: fidalgo, ricome ${ }^{8}$, viãndantes, com origem no português, e fudodinculi e moordomo, com origem latina. Complementarmente, são também formas aglutinadas os nomes próprios Sanyoane (< San[ctum] Iohannem) e Santiago Santyago (< San[ctum] Tiago), os quais não serão analisados neste artigo.

Quanto a fidalgo, o sintagma de que se origina, fllho de algo, constitui um calco morfológico de construções do árabe com 'ibn 'filho' (por exemplo,'iBN YÁumin 'filho de seu dia' = 'efêmero') (Corominas 1983, s.u. hijo). O processo aglutinativo de fllho de algo > fidalgo pode ser traçado da seguinte forma: num primeiro momento, têm-se as duas formas, filho e algo, unidas pela preposição de, numa situação de justaposição. Em um outro momento, ocorre a aglutinação da preposição com o complemento, como nas ocorrências registradas (filho dalgo). Em seguida, o primeiro elemento perde

8 Sobre essas duas formas, fidalgo e ricome, remete-se o leitor para o artigo de Santos (2012). 
a sua sílaba final ( $f$ dalgo), aglutinando-se posteriormente ao segundo constituinte (fidalgo). Nos casos em que o lexema não perde a sua última sílaba, isso pode significar que, para o usuário da língua, ainda subsiste a noção de uma forma composta; por outro lado, quando se chega à forma fidalgo, entende-se que se perdeu essa noção. No entanto, nos textos analisados, é possível encontrar tanto a estrutura sintagmática quanto a forma amalgamada, mais frequente:

- Mandamos que nenhuu fidalgo nõ se possa tornar vassalo de nenguu ata que se espeça de seu sennor quer per sy quer per outrĩ mãdadeyro filho dalgo. (FR III.976)

Quanto a ricomẽ, trata-se de uma forma aglutinada recorrente em alguns textos, dotada da estrutura subjacente Adjetivo + Nome. No Foro Real é possível observar a forma intermediária, ricoome, e a forma já aglutinada, ricomẽ, após a fusão das duas vogais:

- Se el rey ouuer batalha aprazada cũ mouros ou cũ cristaos ou cũ quẽ quer en que aya de seer el ou outro en seu logar per seu mãdado, e ricoome ou infançõ ou outro caualeyro ou outro ome qualquer que seu mandado receber (FR IV.941)

- Todo ricomẽ ou jnfançõ ou outro qualquer que tenha terra ou marauidis dal rey per que deua a fazer hoste, se nõ ueer guysado segũdo como deue quando el rey demãdar e ao logar, perça a terra e os marauidis que teuer dal rey (FR IV.927)

Não foram registradas ocorrências de ricomes, ou seja, de formas cuja variação de número incidisse unicamente no elemento da fronteira direita. Os registros são apenas de ricos omees ( rycos hoomes), com a atuação da flexão sobre os dois elementos, fato que restitui, de certa maneira, à forma o estatuto de justaposto ${ }^{9}$ :

- E isto mandamos tã bẽ por nos come pollos que depoys nos ueerẽ come por rycos hoomes come por caualeyros come polhos outros poboos que demus todos dereytamente os dizimos dos bees que nos dá segundo o que manda a ley (FR I.300)

O aglutinado fudodinculi apresenta feição ainda alatinada, sendo empregado no Foro Real como nome, significando 'sodomita, pederasta' (cf. o glossário do Foro Real 1987, s.u. fudodinculi) ${ }^{10}$ :

9 Ressalte-se, ainda, que nos dicionários de língua portuguesa a forma registrada é rico-bomem, e não ricome ou ricomem.

10 Nas Cantigas d'Escarnho e de Mal Dizer ocorre o termo fududancua (< fududa 'n cuu, conforme Nobiling, 1907, Indice (...), s.u. fududancua.), que, embora empregado apenas como adjetivo, merece 
- Qual quer que [deostar] outro ou lhy disser falso ou trehedor ou fudodinculi ou cornudo ou erege, ou a molher de seu marido disser puta, desdigao ante o alcayde e ant'os omees boos ao prazo que lhy poser o alcayde (FR IV.90)

A forma aglutinada moordomo é derivada do sintagma latino major domus, ocorrendo uma única vez no Foro Real:

- E isto mandamos que seya dos mayordomos (FR III.1001)

A forma viandante não apresenta consenso no que diz respeito ao seu processo histórico de formação. O dicionário de Houaiss e Villar (2009) aponta que viandante 'viajante, pregrino; caminhante' formou-se da forma infinitiva do verbo viandar mais a terminação - nte, marca morfológica do particípio presente e de nomes departicipiais. No entanto, enquanto a forma viandante está registrada no séc. XIII (Foro Real), a forma viandar, no sentido de fazer viagem ou peregrinação, está datada do séc. xviıI (cf. Cunha 1986, s.u. via). O próprio dicionário Houaiss e Villar (2009) registra o séc. XIX, especificamente entre os anos 1817 e 1819, como datação para viandar 'fazer viagem ou peregrinação; vaguear, peregrinar'. Nascentes (1955, s.u. viandante) e Machado (1956/1959, s.u. via) apontam a formação a partir de via + andante. Essa segmentação, segundo Corominas e Pascual (1980-1991, s.u. via), aceitando a hipótese de Meyer-Lübke, se deve a uma alteração do latim vians, -Antis, que foi decomposto em VIA $+\mathrm{AN}(\mathrm{T})$, visto como um derivado do verbo an(d)ar, ocorrendo, daí, a sua prolongação para viandante:

- Os viãdantes possã as bestas ou seus gaados meter a pacer enos logares que nõ sõ sarrados nẽ deffesos (FR IV.368)

Ao se considerar a segmentação morfológica via + andante, tem-se uma estrutura em que o primeiro elemento é um nome, na função de complemento, e o segundo uma forma de particípio presente nominalizado, seguindo a ordem latina determinante + determinado, com o significado de 'o que ou quem anda pela via'.

aqui algumas considerações por alguns aspectos morfossintáticos que apresenta. Destacam-se, nessa forma, o vestígio da preposição em ('n) e a dupla variação de gênero, interna (fududa) e externa (cua ), fazendo-se a concordância com o substantivo "velha": "Ali me desbulharon do tabardo e dos panos / e non ouveron vergonha dos meus cabelos canos, / nen me deron por ende grããs nen adianos; / leixaron-me qual fui nado no meio de la rua; / e un rapaz tinhoso - que o Deus poren [d]estrua! - / chamava-mi "mia nona, velha fududancua!"' [CEMD 71.18]; Em outra ocorrência, é possível verificar, ainda, a flexão de número: "e por esto rogu' eu de coraçon / a Deus que nunca meta semeldon / antre min e velhas fududancuas" [CEMD 45.12], que, nesse caso, diferentemente do gênero, incide sobre toda a estrutura. 

Real.

No Quadro 3, apresenta-se uma síntese dos aglutinados registrados no Foro

\begin{tabular}{|c|c|}
\hline Português $>$ Português & Latim $>$ Português \\
\hline filho de algo $>$ fidalgo & FUTUTUS IN CULUM $>$ fudodinculi \\
\hline rico homem $>$ ricome & MAJOR DOMUS $>$ moordomo \\
\hline *via andante $>$ viãdante & \\
\hline
\end{tabular}

QUADRO 3. AGLUTINADOS

\section{Discussão dos dados}

A observação dos padrões composicionais representados pelos dados retirados do Foro Real $\left([\mathrm{NA}]_{\mathrm{N}},[\mathrm{AN}]_{\mathrm{N}},[\mathrm{NprepN}]_{\mathrm{N}},[\mathrm{AdvN}]_{\mathrm{N}},[\operatorname{PronN}]_{\mathrm{N}}\right.$ e $\left.[\mathrm{NumN}]_{\mathrm{N}}\right)$, e distribuídos no Quadro 1, permite concluir que os mecanismos disponíveis no português e também no galego contemporâneos - cujos exemplos são listados a seguir - já estavam presentes na sincronia galego-portuguesa em estudo:

\begin{tabular}{|c|c|c|}
\hline $\begin{array}{c}\text { Padrão } \\
\text { Composicional }\end{array}$ & $\begin{array}{c}\text { Português (Cunha / Lindley } \\
\text { Cintra 1985: 105-106) }\end{array}$ & $\begin{array}{c}\text { Galego (Dicionario da Real } \\
\text { Academia Galega) }\end{array}$ \\
\hline$[\mathrm{NA}]_{\mathrm{N}}$ & amor-perfeito, criado-mudo & augamariña, arma branca \\
\hline$[\mathrm{AN}]_{\mathrm{N}}$ & alto-forno, belas-artes & boaventura, curtametraxe \\
\hline$[\mathrm{NprepN}]_{\mathrm{N}}$ & chapéu-de-sol, pai de família & ourizo de mar, pan de boroa \\
\hline$[\mathrm{AdvN}]_{\mathrm{N}}$ & bem-aventurança, benquerença & benquerenza, benandanza \\
\hline$[\text { PronN }]_{\mathrm{N}}$ & Nosso Senhor, nossa-amizade & Nosopai \\
\hline$[\mathrm{NumN}]_{\mathrm{N}}$ & mil-folhas, segunda-feira & milfollas, segunda feira \\
\hline
\end{tabular}

QUADRO 4. EXEMPLOS DOS PADRÕES $[N A]_{N},[A N]_{N},[N P R E P N]_{N},[A D V N]_{N}$, $[\text { PRONN }]_{\mathrm{N}} \mathrm{E}[\mathrm{NUMN}]_{\mathrm{N}}$ NO PORTUGUÊS E NO GALEGO CONTEMPORÂNEOS

Não se registraram, contudo, compostos prototípicos, dotados da estrutura $[\mathrm{VN}]_{\mathrm{N}}$ e $[\mathrm{NN}]_{\mathrm{N}}$. Sabe-se, no entanto, que compostos com essas estruturas ocorrem em textos do período medieval, de acordo com o levantamento feito por Santos (2009), do qual resultaram formas como guarda-roupa, guarda-cós, fura buchos, maestre scola, meestre salla e pedra marmor, por exemplo. Dos modelos de composição apresentados, a natureza mais sintática de $[\mathrm{NA}]_{\mathrm{N}},[\mathrm{AN}]_{\mathrm{N}}$ e $[\mathrm{NprepN}]_{\mathrm{N}}$ propicia o aparecimento de formas flexíveis quanto à configuração, seja no que diz respeito à ordem (tabalió publico x publicos tabelliones), seja no que diz respeito à redução do composto ao determinante (carta de pessoaria x pessoaria; manceba en cabelos $\mathrm{x}$ en cabelos). Em 
alguns casos, o núcleo nominal é substituído por uma forma praticamente sinônima: manceba en cabellos $\mathrm{x}$ menia en cabelos:

- se manceba en cabellos casar sen consentimẽto de seu padre ( $F R$ III.53)

- E se for uiuua de boo testemoĩo ou menia en cabelos (FR IV.533)

Também ocorre a possibilidade de outras formas em combinação com o sintagma en cabellos. Nesse caso, há a intercalação de elementos entre o núcleo e o seu modificador:

- Padre nẽ madre nen outro omẽ nõ seya ousado de dar sa filha nẽ outra molher quer seya en cabellos quer uiuoa per força a nẽguu (FR IV.537)

Como já foi referido, as construções filho de beençon e molher de beençon apresentam os respectivos significados: 'filho legítimo' e 'mulher casada na igreja'. Ou seja, o complemento atribui o caráter de "legítimo" ao denotado pelo núcleo. Mais uma vez, poder-se-ia empregar apenas o complemento de forma atributiva: ele é de beençon, ela é de beençon. O emprego de filha de beençon, significando 'filha legítima', não ocorre, mas constitui uma forma possível, uma vez que se tem netos [...] de beençon:

- E se filhos ou netos non ouuer de beençon de molher uelada nẽ outros que aya en dereyto d'erdar, possa fazer do seu o que quiser (FR III.431)

Também no caso de homẽ d'ordẽ e molher d'ordẽ, observa-se a manutenção do sintagma preposicionado, enquanto o núcleo nominal é modificado, constituindo uma oposição genérica de natureza heteronímica.

Os casos supracitados podem ser representados através dos seguintes esquemas, nos quais a variável "X" corresponde a um nome possuidor do traço [+humano], inserido em um paradigma restrito:

$$
\begin{aligned}
& {\left[[\mathrm{X}]_{\mathrm{N}}+\text { en cabellos }\right]_{\mathrm{N}}} \\
& {\left[[\mathrm{X}]_{\mathrm{N}}+\text { de beençon }\right]_{\mathrm{N}}} \\
& {\left[[\mathrm{X}]_{\mathrm{N}}+\text { d'ordẽ }\right]_{\mathrm{N}}}
\end{aligned}
$$

Poder-se-ia aventar que a estrutura de fato fixa é o sintagma preposicionado, o que levantaria dúvidas quanto ao caráter composicional dessas sequências. Cada estrutura, contudo, após preencher o espaço destinado ao núcleo nominal, instancia uma nova referência. 
A série constituída por ordinado (de pistola, dauangelho, de missa) retrata uma situação inversa à das estruturas representadas acima, pois o que se mantém fixo é o núcleo, variando o sintagma preposicionado. Essas construções podem ser representadas pelo seguinte esquema:

$$
[\text { ordinado }+[\text { prepN }]]_{\mathrm{N}}
$$

Além destes casos, lembramos a situação de determinação presente em maestres das chagas, que ocorre juntamente com maestre de chagas. Semanticamente, parece não haver distinção entre as duas formas:

- XVIo. titulo dos fisicos e dos maestres das chagas (FR IV.15)

- Se alguu fisico ou maestre de chagas tomar alguu en guarda a preyto que o saasse e ante que seya saao morrer daquella enfirmidade, nõ possa demandar o preço que auia talhado» (FR IV.796)

Estes compostos $[\mathrm{NprepN}]_{\mathrm{N}}$ representam, portanto, os casos mais problemáticos no âmbito da composição de palavras, por se apresentarem mais flexíveis e menos opacos configuracionalmente, violando as propriedades da fixidez e da integridade lexical, evocadas para distinguir um composto de um sintagma livre. Constituem construções marginais, passíveis de questionamento no que diz respeito ao seu estatuto composicional. Parece necessário conjugarem-se outros conceitos a par do de composição, como o de colocação, visando à interpretação inequívoca de construções com as estruturas $[\mathrm{NA}]_{\mathrm{N}},[\mathrm{AN}]_{\mathrm{N}}$ e, principalmente, $[\mathrm{NprepN}]_{\mathrm{N}}$. Pode se considerar, nesses casos, que as combinações com a estrutura [NprepN], com valor referencial, ou seja, correspondendo a uma unidade semântica, organizam-se também em um contínuo de fixidez estrutural. A reunião de um maior número de ocorrências de uma mesma combinação de palavras, pertencentes a diferentes sincronias, torna-se imperativa para uma discussão mais fundamentada sobre o estatuto (ou não) de composto dessas construções. A fixidez estrutural de algumas combinações de palavras pode ocorrer ao longo do tempo.

Apresentam dados pouco representativos os modelos de composição [AdvN] ${ }_{\mathrm{N}}$, e ainda não muito bem esclarecidos quanto ao seu estatuto morfológico, tendo em vista que o núcleo lexical, em português, em geral se situa à esquerda: malquerer $+-n c ̧(a)$. O constituinte mal- se ligaria, portanto, a verbos, atuando na formação de produtos verbais, e não nominais. Além disso, as duas outras abonações de malcomo primeiro elemento (maldizentes e malfeitor) correspondem a palavras constituídas na língua latina. Também são pouco representativos os padrões composicionais $[\mathrm{NumN}]_{\mathrm{N}}$ e $[\text { PronN }]_{\mathrm{N}}$, pois são ilustrados unicamente por meio dia e Nostro Senhur, respectivamente. 
Em relação aos aglutinados fidalgo e ricomẽ, trata-se de formas resultantes dos sintagmas filho de algo e rico homẽ, respectivamente. É possível, inclusive, observar a coocorrência da forma sintagmática e da forma aglutinada no mesmo texto do Foro Real. Como se pode observar, as estruturas $[\mathrm{NprepN}]_{\mathrm{N}}$ e $[\mathrm{AN}]_{\mathrm{N}}$ estão na base desses aglutinados. Portanto, os nomes aglutinados devem sua estrutura à ação da história, que transforma sintagmas da língua em unidades de sentido e posteriormente essas unidades de sentido em palavras simples, através de processos de erosão fonética. Talvez não se trate, de fato, de palavras compostas, como postulado em gramáticas de língua portuguesa, mas as formas aglutinadas constituem importantes evidências do processo de mudança da língua e, ainda, de enriquecimento do léxico.

\section{Conclusões}

Buscou-se, com este trabalho, atribuir aos compostos, numa perspectiva histórica, o protagonismo que dividem com os processos derivacionais na língua atual. Como vimos, os estudos de natureza histórica voltados para os mecanismos de formação de palavras contemplam principalmente os processos derivacionais. Assim, o estudo de palavras compostas no Foro Real apresenta uma grande relevância, pois, além de envolver a reflexão sobre questões teóricas complexas, como a própria definição de composto, permite o registro da presença de formas que desapareceram da língua portuguesa.

Os compostos registrados no Foro Real contemplam cinco padrões de composição existentes no português e no galego contemporâneos: $[\mathrm{NA}]_{\mathrm{N}},[\mathrm{AN}]_{\mathrm{N}},[\mathrm{NprepN}]$ ${ }_{\mathrm{N}},[\mathrm{NumN}]_{\mathrm{N}}$ e [PronN $]_{\mathrm{N}}($ Cunha / Lindley Cintra 1985: 104; Dicionario da Real Academia Galega). Descartou-se o padrão inicialmente identificado como $[\mathrm{AdvN}]_{\mathrm{N}}$ tendo em vista que duas das três palavras registradas vieram formadas do latim. Além disso, observa-se que, levando-se em conta as regras de formação de palavras que operam em português, a outra palavra, malquerẽça, seria derivada de malquerer.

Os compostos $[\mathrm{NA}]_{\mathrm{N}},[\mathrm{AN}]_{\mathrm{N}}$ e $[\mathrm{NprepN}]_{\mathrm{N}}$ apresentam-se como menos opacos configuracionalmente, o que justifica as ocorrências de tabalió publico x publicos tabelliones, carta de pessoaria $\mathrm{x}$ pessoaria; manceba en cabelos $\mathrm{x}$ menia en cabelos, filho de beençon x molher de beençon, ordinado de pistola x [ordinado] d'auangelho x [ordinado] de missa), por exemplo. A propriedade de integridade lexical, ou opacidade interna, não se apresenta nesses casos. Não obstante, optamos por considerar essas formas como compostos (ou, antes, como potenciais compostos) por apresentarem valor referencial e por poderem vir a apresentar uma maior estabilidade estrutural em textos posteriores ao séc. XIII.

Além dos chamados compostos sintagmáticos, foram referidas algumas formas aglutinadas presentes no Foro Real, como fidalgo, ricome, viãndante, moordomo e fudodinculi. Considerou-se que, no âmbito dessas formas, o grau de analisabilidade 
dos constituintes morfológicos, isto é, o nível de composicionalidade morfológica, é variável. Não é uma condição dos aglutinados a perda da idéia de composição, no entanto, sendo imprevisível como se dará a fusão dos elementos, é possível afirmar que há aglutinados mais ou menos transparentes do ponto de vista do reconhecimento de sua estrutura interna.

\section{REFERÊNCIAS BIBLIOGRÁFICAS}

Blanco VAldés, Xoán L. (1985): "Palabras compostas en galego-portugués”, Verba, 12, 199-252.

Bustos Gisbert, Eugenio de (1986): La composición nominal en español. Salamanca: Ediciones Universidad de Salamanca.

Corominas, Joan (1983): Breve diccionario etimológico de la lengua castellana. Madrid: Gredos.

Corominas, Joan / José A. Pascual (1980-1991): Diccionario crítico etimológico castellano e hispánico. Madrid: Editorial Gredos.

Coutinho, Ismael de Lima (19584): Pontos de gramática histórica. Rio de Janeiro: Acadêmica.

Cunha, Antonio Geraldo da $\left(1986^{2}\right)$ : Dicionário etimológico Nova Fronteira da lingua portuguesa. Rio de Janeiro: Nova Fronteira.

Cunha, Celso / Luís F. Lindley Cintra (1985²): Nova gramática do português contemporâneo. Rio de Janeiro: Nova Fronteira.

González González, Manuel (dir.): Dicionario da Real Academia Galega. A Coruña: Real Academia Galega. http://academia.gal/dicionario\#inicio.do [16/12/2015].

Ferreira, José de Azevedo (ed.) (1987): Afonso X. Foro Real. Edição e estudo lingüístico (vol. I) e glossário (vol. II). Lisboa: Instituto Nacional de Investigação Científica.

Gonçalves, Carlos Alexandre Victorio (2011): "Composição e derivação: pólos prototípicos de um continuum? Pequeno estudo de casos”, Dominios de Lingu@gem, vol. $5(2), 62-89$.

Houaiss, Antônio / Mauro de Salles Villar (2009): Dicionário Houaiss da lingua portuguesa. Rio de Janeiro: Objetiva.

Machado, José Pedro (1956/1959): Dicionário etimológico da língua portuguesa, 2 vols. Lisboa: Editorial Confluência.

Maia, Clarinda de Azevedo (1986): História do Galego-Português. Estado linguístico da Galiza e do Noroeste de Portugal desde o século XIII ao século XVI (com referência à situação do galego moderno). Coimbra: INIC.

Mattoso Câmara Jr., Joaquim (1998 $\left.{ }^{17}\right)$ : Problemas de lingüística descritiva. Petrópolis: Vozes.

Meillet, Antoine / Joseph Vendryes (1953²): Traité de grammaire comparée des langues classiques. Paris: Librairie Ancienne Honoré Champion. 
Moyna, María Irene (2011): Compound Words in Spanish. Theory and history. Amsterdam / Philadelphia: John Benjamins Publishing Company.

Nascentes, Antenor (1955): Dicionário etimológico da língua portuguesa, t. I. Rio de Janeiro: Livraria Acadêmica.

Nunes, José Joaquim (19565): Compêndio de gramática histórica portuguesa (fonética e morfologia). Lisboa: Livraria Clássica Editora.

Nobiling, Oskar (1907): As Cantigas de D. Joan Garcia de Guilhade (trovador do século XIII). Edição crítica, com notas e introdução. Erlangen: K. B. Hof- und Univ.-Buchdruckerei von Junge e Sohn.

Ribeiro, Sílvia (2010): Compostos nominais em português: as estruturas VN, NN, Nprep e $N A$. München: Lincom.

Ribeiro, Sílvia (2006): Compostos nominais em português: as estruturas VN, NN, NprepN e NA. Dissertação de Mestrado. Coimbra: Faculdade de Letras da Universidade de Coimbra.

Ribeiro, Sílvia / Graça Rio-Torto (2013): "Composição”, em Graça Rio-Torto et al., Gramática derivacional do português. Coimbra: Imprensa da Universidade de Coimbra, 385-431.

Rio-Torto, Graça / Sílvia Ribeiro (2009): “Compounds in Portuguese”, Lingua e Linguaggio VIII (2), 271-291.

Rio-Torto, Graça / Sílvia Ribeiro (2012): “Portuguese compounds”, Probus 21 (1), 119-145.

SAID Ali, Manuel (1964³): Gramática bistórica da lingua portuguesa. São Paulo: Melhoramentos.

SAntos, Antonia Vieira dos (2009): Compostos sintagmáticos nominais VN, $N N, N A, A N$ e NprepN no português arcaico (sécs. XIII-XVI). Tese de Doutorado (inédita), 2 vols. Salvador: Instituto de Letras - Universidade Federal da Bahia.

SAntos, Antonia Vieira dos (2012): "Do composto sintagmático ao lexema aglutinado: consequências morfológicas e sintáticas”, em Rosa Virgínia Mattos e Silva / Klebson Oliveira / José Amarante (orgs.), Várias navegaçôes: português arcaico, português brasileiro, cultura escrita no Brasil, outros estudos em homenagem a Therezinha Barreto. Salvador: EDUFBA, 239-258.

Val Álvaro, José (1999): “La composición”, em Ignacio Bosque / Violeta Demonte (dirs.), Gramática Descriptiva de la Lengua Española. Vol. III: Entre la oración y el discurso. Morfologia. Madrid: Editorial Espasa, 4757-4842. 
